\title{
A Research on Incubation Effectiveness of Enterprise Innovative Talents in China
}

\author{
Qianwen Li \\ Wuhan University of Technology \\ Management School \\ Wuhan, China \\ 424228293@qq.com
}

\author{
Shan $\mathrm{He}^{*}$ \\ Wuhan University of Technology \\ Management School \\ Wuhan, China \\ whutheshan@163.com
}

\begin{abstract}
This paper divides innovative talents into managing talents and technological talents to study the influence of all investment in incubation respectively with distributed lag model and D-G production function. The results indicate that the "leverage effect" of incubation was very obvious, and the investment in incubation can bring more significant benefits. Particularly the capital investment of innovative talent incubation can bring quickly outputs in the short term, while the human resource investment has a 2 3-year time lag.
\end{abstract}

Keywords-innovative talents; incubation efficiency; distributed lag model; D-G production function

\section{INTRODUCTION}

At present, China's has stepped into the "new normal" phase of economic development with growth rate less than 7 percent, comparing to be the "old normal" during the 35 years between 1978 and 2013, when annual growth of the Chinese economy averaged close to 10 percent. "New" means that it is different from the past, and "Normal" means the slowing momentum will persist for a long period[1]. The good old days cannot last forever, the Chinese economy has embarked on a new track featuring a shift from high-speed growth to medium-high growth, a shift from quantity and speed to quality and efficiency, and a shift from factor-driven and investment-driven to innovation-driven[2]. Innovative talents are becoming the source of vitality for enterprises, and will have decisive impact on the future enterprise sustainable growth. Because the process of mastering incubating innovative talents and improvement of incubation efficiency can reduce operating costs, shorten incubation period and form new growth incentives.

With the extensive concern on enterprise's technology innovation and core competency, an increasing number of authors have researched on innovative talent incubation. Qingxian $\mathrm{Wu}$, Zeheng Fan studied from multi-dimension perspective and found the direct relationship between innovative talents training and enterprise institutional system[3]. Xiaowen $\mathrm{Li}$ insisted the importance of "cultivation" of potential young technical and scientific staff and improvement of incentive mechanism[4]. Xi Zhao, Long Ye researched from psychological perspective, argued that feedback mechanism and good corporate culture could stimulate the progress of innovative talents[5].
Prior studies focusing on the importance of innovative talents and have shown innovative talents have a positive effect on the enterprise competiveness. However, the quantitative explanation of these studies on the benefits of innovative talent incubation is limited to a certain extent. Thus, in order to fully explain the effect of innovative talent cultivation on enterprise innovative performance, the current study adopts improved Cobb-Douglas production function, takes enterprise investment and enterprise development as influencing factors, and calculates incubation efficiency of innovative talents.

The remainder of this paper is organized as follows. First, we will discuss the role of innovative talent incubation, and the basic principles in explaining the innovative performance of firms. Second, we will construct the concept model of innovative talent incubation system. Next, we will empirically test our hypotheses using a time series dataset of enterprise innovative talent incubation. Finally, in the discussion section, we will present and discuss the results and policy suggestion upon the conclusions of this study.

\section{BASIC PRINCIPLES AND ASSUMPTIONS}

This paper sets up an innovative talent incubation system as shown in figure 1, the incubation efficiency is calculated based on the system's input and output, and the controllable and uncontrollable factors are not separated and studied. A number of prior studies have taken innovative talents as research subject, but it is relatively difficult to probe the quantity and quality of innovative talents incubation. As the ultimate purpose of innovative talents incubation system is economic benefits, this paper takes enterprise as the research subject, considers human investment and capital investment as input and enterprise profits as the output of the system..

It requires enterprises not only financial support but also a long period of time to cultivate innovative talents. There is a lag effect in the innovative talents incubation, meanwhile cumulative changes would also affect the current situation in the process and efficiency of personnel training, in other words, the value of innovative incubation output is associated with its past levels. This paper used distributed lag model to estimate innovative talents incubation period. On the basis of the research results of Sang H Wong [6], it is hypothesized that there are only capital and labor inputs of innovative talents in the process of production; and the capital investment 
of innovative talents incubation and labor inputs may be substituted for each other.

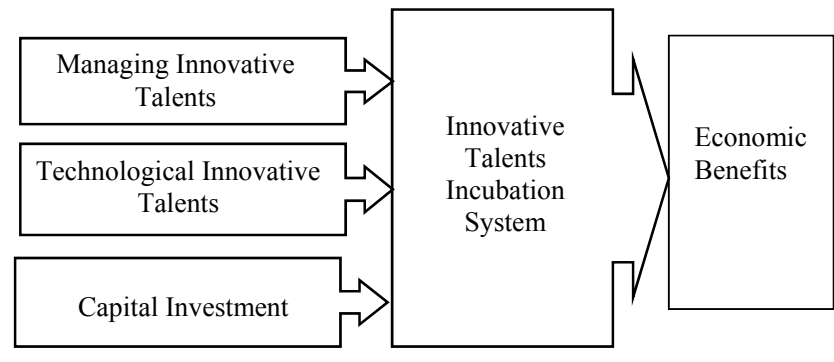

Fig. 1. Innovative talents incubation system

The general form of distributes lag model is:

$$
Y_{t}=\alpha+\beta_{0} X_{t}+\beta_{1} X_{t-1}+\beta_{2} X_{t-2}+\cdots+\beta_{s} X_{t-s}
$$

In which, Y represents economic benefits; $\mathrm{X}$ is innovative talents input variables; $t-1$ is the length of lagged explanatory variables; $\mathrm{s}$ is lag period when $\mathrm{R}$-squared gets maximum value.

According to the traditional Solow model, improved D-G production function is:

$$
Y_{t}=A_{t} K_{t}^{\alpha}\left(M_{t-S_{1}}^{\beta_{1}} \bullet R_{t-s_{2}}^{\beta_{2}}\right)
$$

$Y_{t}$ is enterprise's economic benefits in t years. $A_{t}$ is enterprise's efficiency of innovative talents incubation in $\mathrm{t}$ years. $K_{t}$ is enterprise's capital investment in innovative talents inputs in $\mathrm{t}$ years. $M_{t-s_{1}}$ is enterprise's managing innovative talents inputs in t-s1 years. $R_{t-s_{2}}$ is enterprise's research innovative talents in $\mathrm{t}-\mathrm{s}_{2}$ years. And $0<\alpha<1,0<\beta_{1}<1,0$ $<\beta_{2}<1$.

In actual production, the inputs contain all aspects of capital investments and labor investment in the corporate. The model in this paper is reducible and simplified to measuring the relationship between inputs and output in the system, the efficiency of innovative talents incubation calculated doesn't make an absolute meaning, but relative meaning when making horizontal or vertical comparing.

\section{DATA AND METHOD}

\section{A. Model design}

Take the logarithm on the both sides of the formula (2) to eliminate multicollinearity:

$$
\ln Y_{t}=\ln A_{t}+\alpha \ln K_{t}+\beta_{1} \ln M_{t-s_{1}}+\beta_{2} \ln R_{t-s_{2}}
$$

Take derivative on the both sides of the formula (2) to get the growth rate formula (3):

$$
Y_{t}^{\prime}=A_{t}^{\prime}+\alpha K_{t}^{\prime}+\beta_{1} M_{t-s_{1}}^{\prime}+\beta_{2} R_{t-s_{2}}^{\prime}
$$

In the formula (4), $Y_{t}^{\prime}$ is the change rate of economic benefits in $t$ years. $A_{t}^{\prime}$ is the change rate of innovative talents incubation efficiency in $\mathrm{t}$ years. $K_{t}^{\prime}$ is the change rate of capital investment in innovative talents incubation. $M_{t-s_{1}}^{\prime}$ is the change rate of managing innovative talents inputs in $t-s_{1}$ years. $R_{t-s_{2}}^{\prime}$ is the change rate of technological innovation talents in $\mathrm{t}-\mathrm{s}_{2}$ years.

\section{B. Variables}

To do empirical research, we collect time series data in 2006-2014 of the industrial enterprises above designated size from the "Chinese Science and Technology Statistical Yearbook" and national bureau of statistics website.

For each year of the observation period, the procession of variable selection as follows:

1) The economic benefits in enterprise innovative talents incubation ( $Y$ ): this variable is outputs in the procession of enterprise innovative talents incubation, which is measured by the enterprise product sales revenue.

2) The efficiency of enterprise innovative talents incubation (A): it is the ratio of enterprise innovative talents incubation input and output.

3) Enterprise capital investments to innovative talents incubation (K): this variable is the funds invested in the process of enterprise innovative talents incubation. The data is new product research expenditure of industrial enterprises above designated size.

4) Innovative Management talents inputs (M): this variable is the number of managing talents inputs in the process of enterprise innovative talents incubation. Because detailed data are not available, data selects $2 \%$ secondary industry employment representation according Rassameeths and Westbrook's calculation.

5) Innovative technical talents input $(R)$ : this variable is the number of technical innovation talents in the process of enterprise innovative talents incubation. The data are $R \& D$ personnel full-time equivalent in enterprises above designated size.

In the calculation of the rate of indicators changing in the formula (4), we chose year-on-year basis to calculate the ratio, the difference between the amount of current year and previous year divided by the amount of the current year.

\section{Lag terms estimates}

$\mathrm{S}$ Select $\mathrm{M}, \mathrm{R}$ as the explanatory variables, $\mathrm{Y}$ as the dependent variable. And estimate the formula (1) by OLS method. The results are as follows in Table 1.

The coefficient of determination of $\mathrm{M}$ up to 0.8661 when $\mathrm{s} 1=3$, so the lag period of innovative management talents as input in the enterprise innovative talents incubation system is 3 year. When $\mathrm{s} 2=2$ the coefficient of determination of $\mathrm{R}$ up to 0.9964 , so that the lag period of technological innovative talents as input is 2 year. 
TABLE I. THE COEFFICIENT OF DETERMINATION OF FORMULA (1)

\begin{tabular}{|c|c|c|}
\hline $\mathbf{X}$ & $\begin{array}{c}\text { The number of } \\
\text { innovative management } \\
\text { talents (M) }\end{array}$ & $\begin{array}{c}\text { The number of } \\
\text { innovative technical } \\
\text { talents (R) }\end{array}$ \\
\hline 0 & 0.42936 & 0.9903 \\
\hline 1 & 0.5066 & 0.9903 \\
\hline 2 & 0.4973 & 0.9964 \\
\hline 3 & 0.8661 & 0.9953 \\
\hline
\end{tabular}

Combined with delayed effects, formula (3) is:

$\ln Y_{t}=\ln A_{t}+\alpha \ln K_{t}+\beta_{1} \ln M_{t-3}+\beta_{2} \ln R_{t-2}$

Formula (4) is:

$$
Y_{t}^{\prime}=A_{t}^{\prime}+\alpha K_{t}^{\prime}+\beta_{1} M_{t-3}^{\prime}+\beta_{2} R_{t-2}^{\prime}
$$

\section{RESULTS}

Calculated on the formula (5) with Eviews 9.0, the results are as follows:

$\ln Y_{t}=4.8512+0.7458 \ln K_{t}+0.1641 \ln M_{t-3}+0.2157 \ln R_{t-2}$ $R^{2}=0.9776$ indicates formula (5) fit well with the sample. At the significance level of $0.05, \mathrm{~F}=73.6419>F_{\alpha}(3,3)=9.28$ shows that regression equation is significant, and "Enterprise capital investments to innovative talents incubation (K)", "The number of innovative management talents (M)" and "The number of innovative technological talents (R)" impact "the economic benefits in enterprise innovative talents incubation (Y)" significantly. When $\mathrm{n}-\mathrm{k}=3, \mathrm{t}=3.182$, only "Enterprise capital investments to innovative talents incubation (K)" has positive significant impact, the impact of "The number of innovative management talents (M)" and "The number of innovative technological talents (R)" are positive but not obvious.

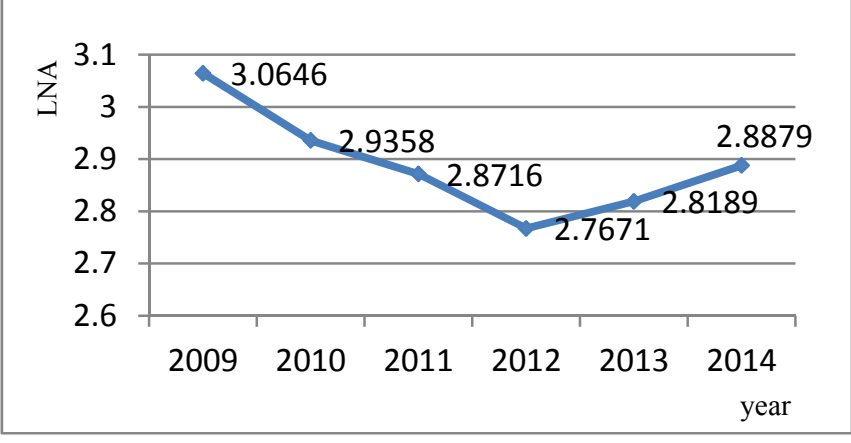

Fig. 2. The efficiency of enterprise innovative talents in 2009-2014(LNA)

Based on formula (5), the efficiency of enterprise innovative talents incubation (LNA) from 2009-2014 are calculated, and the results are shown in figure 2. It reveals that the efficiency of enterprise innovative talents incubation has been declining in 2009-2012 years, and the efficiency of enterprise innovative talents incubation has risen in 2013-2014.

The results of formula (6) are as follows:

$$
Y_{t}^{\prime}=0.0067+0.1429 K_{t}^{\prime}+0.0354 M_{t-3}^{\prime}+0.0815 R_{t-2}^{\prime}
$$

$R^{2}=0.9373$ explains that the formula (6) fit well. When $\alpha=0.05, \mathrm{~F}=20.9469>\mathrm{F}_{\alpha}(3,4)=6.59$, which means the regression equation is significant. When $\alpha=0.05, \mathrm{t}_{\alpha} / 2(4)=2.776$, and $\mathrm{t}$ values of variables $K_{t}^{\prime}, M_{t-3}^{\prime}$ were 1.2395 and 1.5103 , which are less than 2.776. The t-value of $R_{t-2}^{\prime}$ is 5.3555 more than 2.776. The results show that the increasing of "Enterprise capital investments to innovative talents incubation (K)" and "the number of innovative management talents (M)" has insignificant impact on new product revenue growth, while the increasing of technical talents has a significant impact on sales of new product.

The A calculated in formula (2) is greater than 0 , which means the incubation of the industrial enterprises above designated size has high efficiency, the investment in labor and capital can bring significant sales revenue increase. Affected by the 2008 financial crisis, the efficiency of innovative talents incubation decreased from 2009 to 2012. To facilitate the leading role of technology innovation in economy and social development, the State Council of China issued "The Opinions on Deepen Reform of the Science and Technology System and Accelerate Construction of the National Innovation System" in 2012, which makes the efficiency increasing gradually in 2012 2014.

The value $\alpha$ in formula (5) is 0.7458 , comparing with the increase in the quantity of innovative talents, the increase of input to innovative talents incubation has higher significant effect on sales income of new products. $\beta 1=0.1641$ means that there is a positive correlation between the number of innovative management talents and sales of new products, and the impact on sales income of innovative management talents is less than technical talents. $\beta 2=0.2157$ means that there was a positive correlation between the number of technical talents and sales of new products, while the influence wasn't significant.

$\alpha+\beta 1+\beta 2>1$ means that is increasing returns to scale of enterprise innovative talents incubation. Given the situations that other conditions remain unchanged, the increase at the same rate of capital input, innovative management talents and technical talents, will create higher output increase, in other words, the output increase rate of the incubation system is larger than that of the input factor. The reason is that a higher level of professional staff would improve the efficiency of enterprise innovative talents incubation system, and the integrity of the system can achieve intensive use of the resources and reduce the cost of incubation.

In formula (6), the increasing inputs of innovative management talents and technical innovative talents would promote the sales revenue of new products, but not as significant as the capital investments. The results of formula (5) show that the influence of the increase of technical talents on outputs is more obvious than the increase of innovative management talents. This is due to the selection of technical talents is more objective under academic achievement criteria such as patents granted, papers published and so on, while the selection of innovative management talent is relative more subjective, moreover, technical talents impact on product 
quality, quantity or production efficiency directly while the influences of management talents are indirectly.

\section{CONCLUSION}

The "new normal" of China's economy will last for a long period, the Chinese economy will transform from the production investment-driven model into an innovation-driven model. The prolonged difficulties facing manufacturing industries show China can no longer rely on low cost production factors, as the prices of labor, resources and land are soaring. As major players in economic activities and technological innovation, enterprises should reform innovative philosophy, increase innovation investments to enhance growth quality and efficiency.

The findings of this study have important implications for management. Through empirical analysis using D-G Production Function, it is found that the capital investments in the process of innovative talents incubation can be converted to innovation outputs more quickly than the increase of innovative talents. However, the inputs of human resources are the premises and catalysts of the incubation system, this implies that managers should carefully consider the role of innovative talents and improve the efficiency of the incubation system. The innovative talents are divided into management talents and technical talents in this paper, the impacts of management talents are less than technical talents, while the incubation period of technical talents is longer than management talents. How to shorten the period of incubation is the key to improve the enterprise creativity and reduce the cost.
On policy recommendations, this paper argues that governments and relevant agencies should increase the financial support for the innovative talents incubation especially in high-tech enterprises to reduce the funding burden on innovation. It is necessary to consummate incubation mechanism to improve the efficiency of innovative talents incubation. First of all, consummate personnel selection systems to select innovative potential talents to reduce the cost and shorten the period. Second, consummate the process of talents incubation to regulate enterprise and talents behavior. At last but not least, consummate the examination system to grasp the overall situation.

\section{REFERENCES}

[1] Wei Liu, Jian Su, "Chinese Macro under "New Normal", .Economic Science, 2014,4:5-13

[2] Minji Li, "The Key to Transform the Way to Develop Economy: From Factor-driven to Innovation-driven". New Horizons 2013,2:26-28

[3] Qingxian Wu, Zehuan Fan, "To Find Innovative Breakthroughs Talents in Multi-dimension. Chinese" University Teaching, 2012, 2:77-79.

[4] Xiaowen Li. "A Research on The Training and Introduction of Innovative Talents simply", Science and Society, 2013:3(3):35-37.

[5] Xi Zhao, Long Ye. "Knowledge Worker Psychological Contract Violation Mechanism and Digestion", Jiangxi Social Sciences, 2015, 2:225-230.

[6] Sang H Wong, "Fire Sprinkler CADD and Engineering Economics", PM Engineer, 2004,9(10). 